\title{
A Study on the Effects of Nifedipine in Hypertensive Crises and Severe Hypertension
}

\author{
Iwao Kuwajima, M.D., Keiji Ueda, M.D., Chizuko Kamata, M.D., \\ Satoru Matsushita, M.D., Kizuku Kuramoto, M.D. \\ Mototaka Murakami, M.D., and Yoshiyuki Hada, M.D.*
}

\section{Summary}

Ten mg of Nifedipine, a $\mathrm{Ca}^{++}$antagonist, was administered orally in 2 groups of patients; Group I : 6 patients in hypertensive emergency and Group II : 12 patients with intractable, severe hypertension. Following results were obtained. 1) A marked hypotensive effect was observed in all patients of Group I. The maximum effect was observed within 30 to $60 \mathrm{~min}$ and lasted for approximately $180 \mathrm{~min}$. Clinical symptoms also improved remarkably with the fall in blood pressure. Any side effect was not observed. 2) A marked hypotensive effect was observed in all cases of Group II. The blood pressure fell by $21.4 \%$ systclic $(p<0.01)$ and $19.4 \%$ diastolic $(p<0.02)$. The peripheral vascular resistance also showed the decrease by $26.2 \%(\mathrm{p}<0.01)$. The heart rate and cardiac index increased slightly.

It was suggested that the hypotensive mechanism of this preparation is due primarily to the peripheral vasodilatation.

\section{Additional lndexing Words :}

$\mathrm{Ca}^{++}$antagonists Hemodynamics in hypertension Left ventricular dimension on echocardiogram Hypertensive emergency Intractable hypertension mainly used in the treatment of coronary heart disease. Nifedipine, 4-(2'-nitrophenyl)-2, 6-dimethyl-1, 4-dihydropyridine-3, 5-dicarboxy-dimethylester, was investigated as to its hypotensive effect by Murakami' ${ }^{1)}$ and Aoki ${ }^{2}$ and their co-workers, in addition to its established antianginal action.

In an open trial, we administered Nifedipine to patients in hypertensive emergencies, and with prolonged, severe hypertension, not responding to other standard hypotensives.

Besides the blood pressure lowering action of Nifedipine, hemodynamic

From the Division of Cardiology, Tokyo Metropolitan Geriatric Hospital, 35-2 Sakaecho, Itabashi-ku, Tokyo 173, Japan.

* Second Department of Internal Medicine, Faculty of Medicine, University of Tokyo.

Received for publication November 14, 1977 
changes and occurrence of adverse reactions attributable to the drug were investigated.

\section{Study Group and Method}

Eighteen patients, 11 men and 7 women, from 35 to 85 years old (mean age; 63.1), admitted to Tokyo Metropolitan Geriatric Hospital were selected for the trial. These patients were divided into the following groups;

Group I (hypertensive crises) consisted of 3 men and 3 women, 64-77 years old (mean age 69.5), with a sudden, marked rise in blood pressure, accompanied by clinical symptoms suggestive of hypertensive encephalopathy such as disturbances of consciousness and convulsions, requiring emergency measures to lower the elevated blood pressure.

Underlying disorders in these cases were cerebrovascular accident in 3 patients, renal insufficiency in 1 and unknown in other 2 patients.

Blood pressure before treament with Nifedipine was, on the average, 236.7 $\mathrm{mmHg}$ (range : from 202 to $290 \mathrm{mmHg}$ ) systolic and $109.7 \mathrm{mmHg}$ (range : from 80 to $150 \mathrm{mmHg}$ ) diastolic. After measuring blood pressure and pulse rate, $10 \mathrm{mg}$ of Nifedipine were administered orally. Three patients with disturbance of consciousness received the drug dissolved in $10 \mathrm{ml}$ of water via a gastric tube. Blood pressure was recorded $30,60,120$, and $180 \mathrm{~min}$ after oral administration. Three patients, who received Nifedipine via a gastric tube had an additional blood pressure measurement $10 \mathrm{~min}$ after the administration.

Group II (severe hypertension) consisted of 8 men and 4 women from 35 to 85 years old (mean age; 59.9) with blood pressure exceeding $200 \mathrm{mmHg}$ systolic or exceeding $110 \mathrm{mmHg}$ diastolic, persisting for more than 1 month. The patients could not be managed by mono- or combination therapy with thiazide, $\alpha$-methyl dopa, $\beta$-blocker or hydralazine. Nine patients were diagnosed as essential hypertension, 2 as renovascular hypertention, and 1 as renal hypertension.

Blood pressure before thrapy with Nifedipine was, on the average, $205.1 \mathrm{mmHg}$ (range; from 170 to $226 \mathrm{mmHg}$ ) systolic and $113.3 \mathrm{mmHg}$ (range; from 90 to 140 $\mathrm{mmHg}$ ) diastolic. Blood pressure, heart rate and following hemodynamic parameters were measured before and $30 \mathrm{~min}$ after oral administration of Nifedipine. Left ventricular dimensions in end-diastole and in end-systole were measured and ejection fraction was calculated on echocardiogram recorded by Aloka SSD 110 in 8 patients before and after the drug administration.

Circulating blood volume was determined by injection of Evans blue with patients in supine position. Cardiac output was measured by dye dilution method with indocyanine green. Dye dilution curve was recorded with Elma-Densitograph EN 80 and cardiac output was calculated with Elma-Computer EW 90.

\section{REsults}

Group I; As shown in Fig. 1, a marked hypotensive effect was observed in all cases within $60 \mathrm{~min}$ after the administration of Nifedipine. In 3 patients with gastric intubation, a fall of blood pressure occurred $10 \mathrm{~min}$ after the 


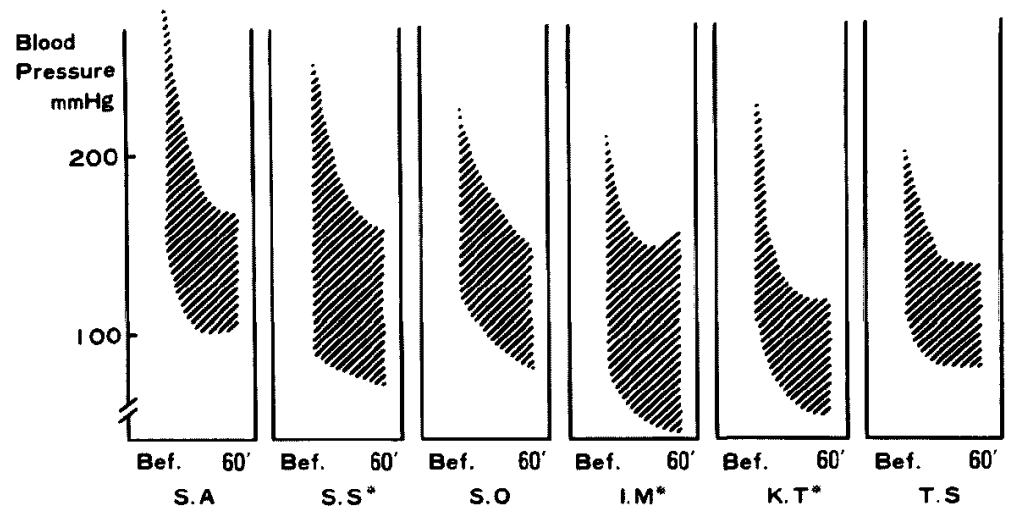

Fig. 1. Effect of Nifedipine in hypertensive crises. ※: via a gastric tube.

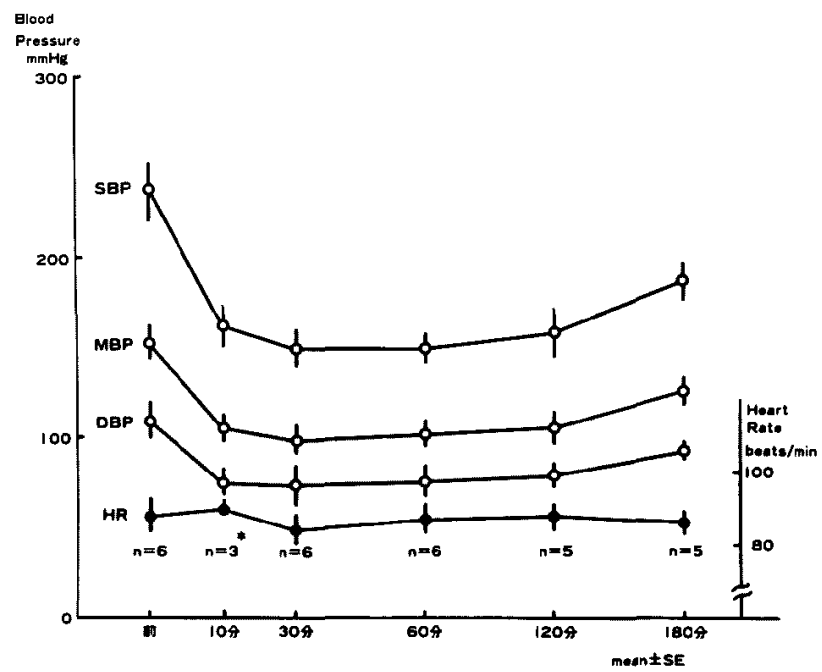

Fig. 2. Time course of blood pressure and pulse rate following oral administration of Nifedipine. Bars denote mean values +SEM.

administration of the drug. With a fall of blood pressure, all patients showed improvement of their clinical symptoms. Adverse drug reactions attributable to Nifedipine therapy were not observed.

Blood pressure and pulse rate before administration of Nifedipine and their changes up to 180 min after the drug administration are shown in Fig. 2. The maximum hypotensive effect was obtained within 30 to $60 \mathrm{~min}$ and lasted for over $180 \mathrm{~min}$. Pulse rate showed no significant changes (Table I).

Following is a representative case; (Case 5; K.T.)

A 72-year-old man developed left hemiplegia due to cerebral apoplexy on September 18, 1976. In December 1976, he was admitted to Tokyo Metropolitan Geriatric Hospital for rehabilitation training. 


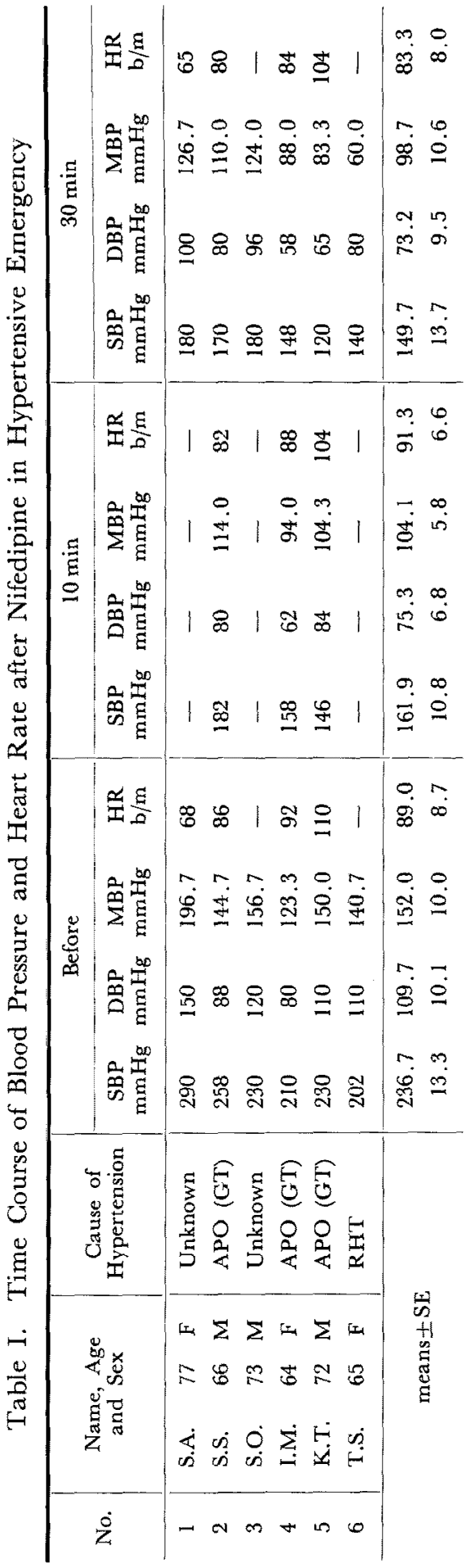

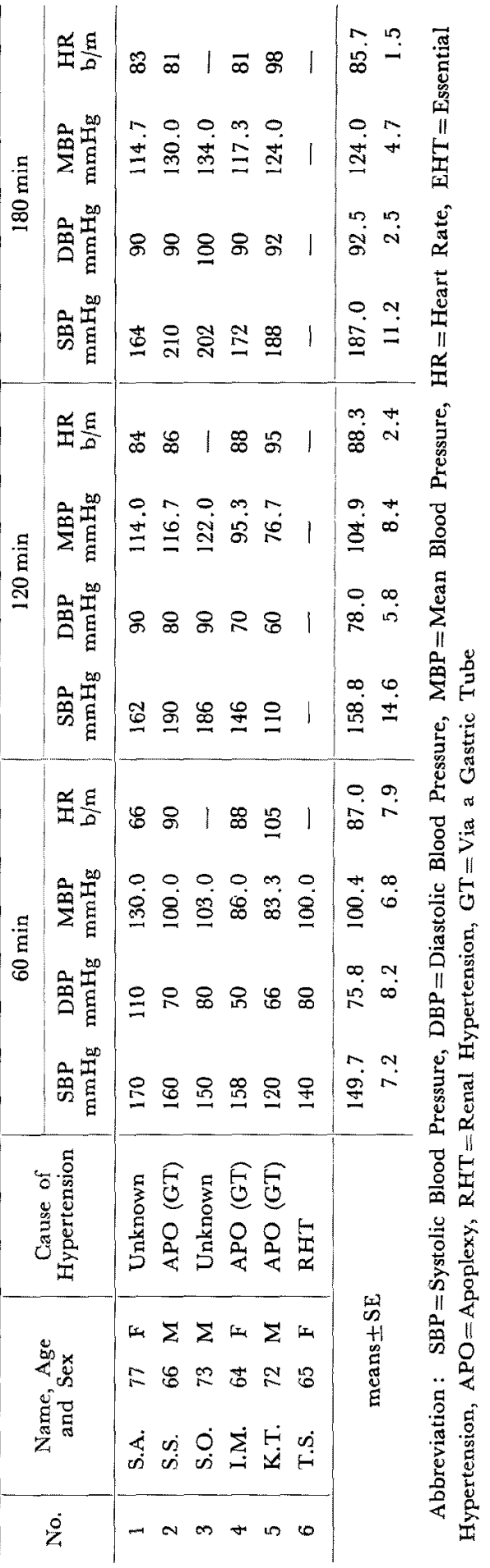


Physical examination on admission revealed blood pressure 166/86 $\mathrm{mmHg}$, heart rate $88 / \mathrm{min}$ regular, no abnormalities on cardiac and pulmonary auscultation, mild dementia, left hemiplegia and presence of pseudobulbar paralysis. Cardiothoracic ratio was $60 \%$ on the chest X-ray film and the electrocardiogram showed left ventricular hypertrophy.

After the admission, the patient's blood pressure ranged from 120 to 160

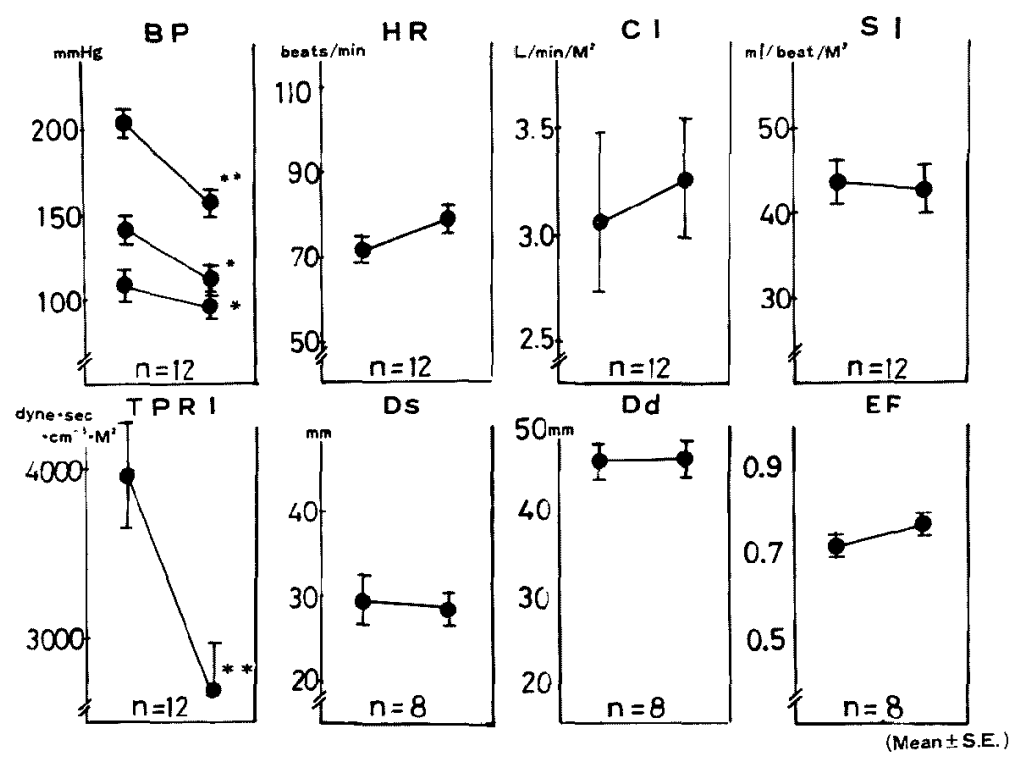

Fig. 3. Hemodynamic changes $30 \mathrm{~min}$ after Nifedipine in severe hypertension. ${ }^{*} \mathrm{p}<0.02,{ }^{* *} \mathrm{p}<0.01$.

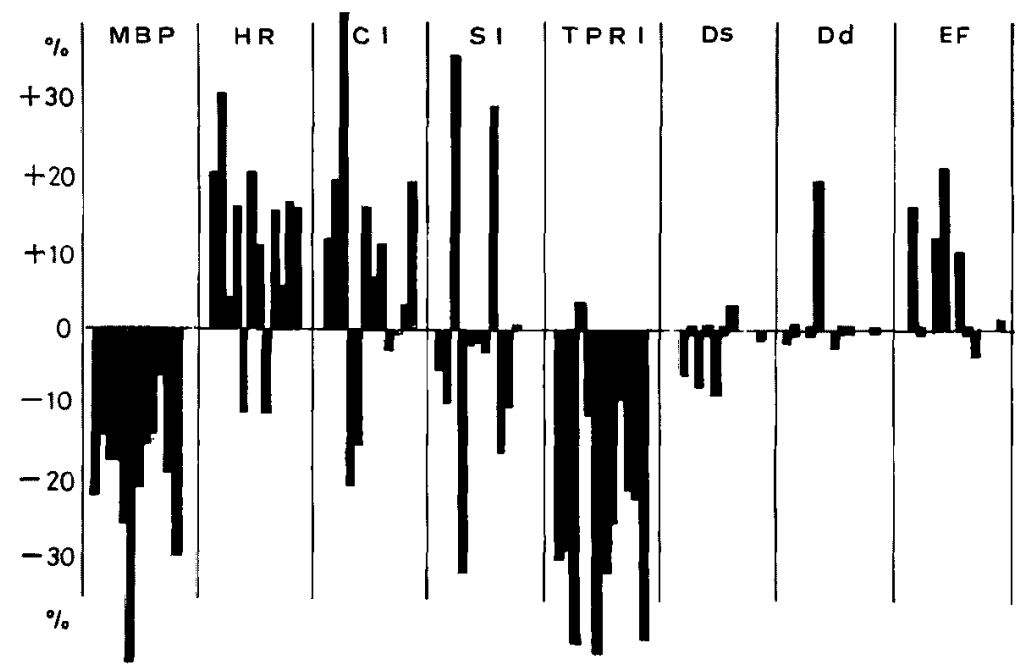

Fig. 4. Changes of hemodynamic parameters in per cent after Nifedipine in severe hypertension. 


\begin{tabular}{|c|c|c|c|c|c|c|c|}
\hline 画 & & 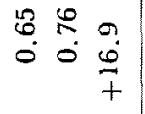 & 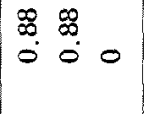 & & 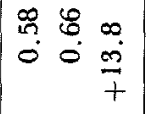 & 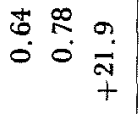 & 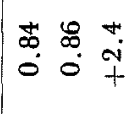 \\
\hline 官高 & & $\begin{array}{lll}0 & v & 0 \\
\dot{0} & \infty & 0\end{array}$ & $\begin{array}{l}0 \\
\dot{\phi} \\
\dot{\phi}\end{array}$ & & $\stackrel{0}{\dot{\varphi}} \dot{+} 0$ & $\stackrel{\circ}{\circ} \stackrel{\circ}{\circ} \stackrel{\circ}{+}$ & $\stackrel{\circ}{\dot{q}} \stackrel{0}{q} 0$ \\
\hline 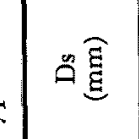 & & $\begin{array}{lll}N & N & \sim \\
\cdots & \infty & 1\end{array}$ & 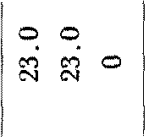 & & $\begin{array}{lll}0 & 0 & 1 \\
\ddot{\infty} & \infty & 0\end{array}$ & 웅ํㅇ & 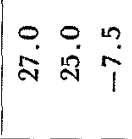 \\
\hline 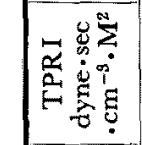 & 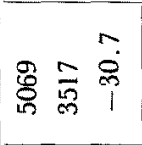 & 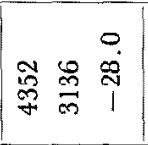 & 志令 & 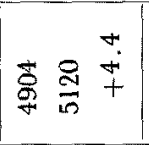 & 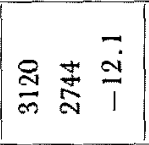 & $\begin{array}{lll} & & n \\
\infty & \approx & \text { in } \\
\infty & \infty & 1\end{array}$ & 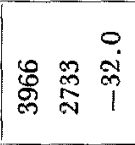 \\
\hline क & $\vec{m} \bar{m}$ & 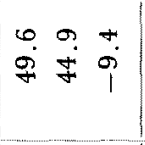 & 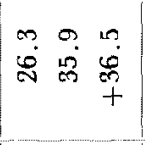 & 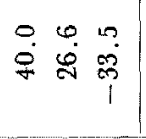 & वृ & $\overrightarrow{\text { जิ }}$ & 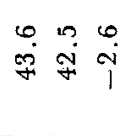 \\
\hline 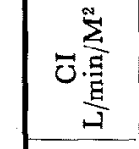 & $\begin{array}{ll}\overrightarrow{0} & \stackrel{8}{a} \\
\sim & \stackrel{m}{+}\end{array}$ & 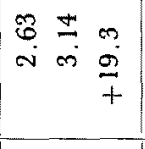 & 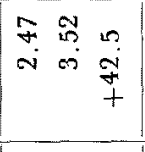 & 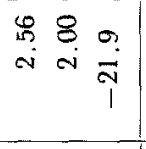 & 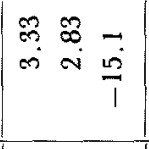 & 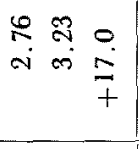 & $\begin{array}{ccc}5 & \stackrel{0}{N} & \infty \\
\text { का } & \text { m } & \dot{0} \\
& & +\end{array}$ \\
\hline 莡 & 웋 & 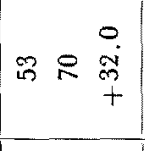 & $\dot{\sigma} \dot{\sigma}+$ & $4: \frac{7}{5}$ & $\infty \cong \stackrel{\infty}{=}$ & ज & $\approx \mathscr{\overline { t }}$ \\
\hline 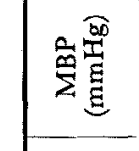 & 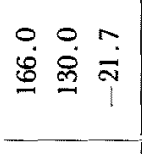 & 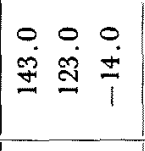 & 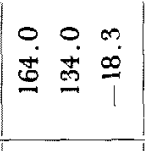 & 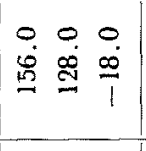 & $\begin{array}{lll}0 & 0 & \sim \\
\dot{g} & \dot{8} & \dot{\pi} \\
& 1\end{array}$ & 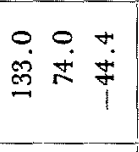 & 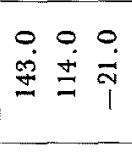 \\
\hline 总 & 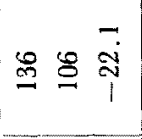 & $\varrho \sigma \frac{\varphi}{\dot{ \pm}}$ & $\stackrel{g}{ \pm} \frac{\ddot{N}}{1}$ & $\stackrel{\Xi}{=} \frac{m}{1}$ & $\triangleq 尺 \stackrel{\ddot{\oplus}}{\dot{0}}$ & 8 윰 & ㅇ ซै \\
\hline 鱼弮 & ஸิ & 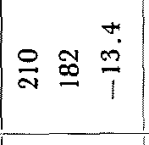 & 苏落 & $\frac{0}{\sim} \stackrel{0}{0}$ & 오욤 & \&્ㅇํำ & 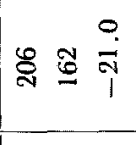 \\
\hline & 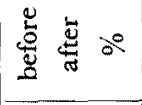 & 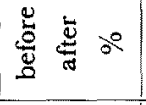 & $\stackrel{\square}{\square}$ & 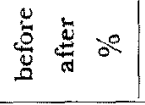 & 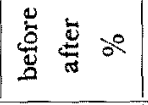 & 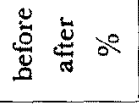 & 总 总 \\
\hline 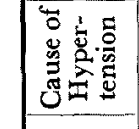 & $\stackrel{E}{\stackrel{E}{2}}$ & 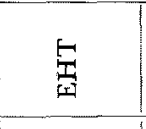 & $\sum_{x}^{5}$ & $\underset{x}{E}$ & 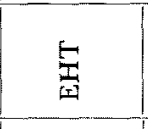 & 穿 & $\underset{1}{5}$ \\
\hline 茹 & 8 & $\frac{5}{0}$ & 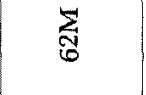 & $\frac{\Sigma}{n}$ & 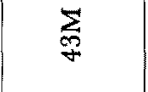 & 8 & $\sum_{\substack{n \\
\text { m }}}$ \\
\hline 乙ूँ & $\begin{array}{l}\dot{0} \\
\dot{z}\end{array}$ & $\frac{d}{z}$ & $\stackrel{0}{\dot{d}}$ & ri & $\stackrel{\leftrightarrow}{H}$ & $\dot{\vec{i}}$ & 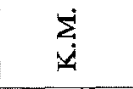 \\
\hline$\dot{z}$ & - & N & $\because$ & + & in & $\infty$ & $n$ \\
\hline
\end{tabular}




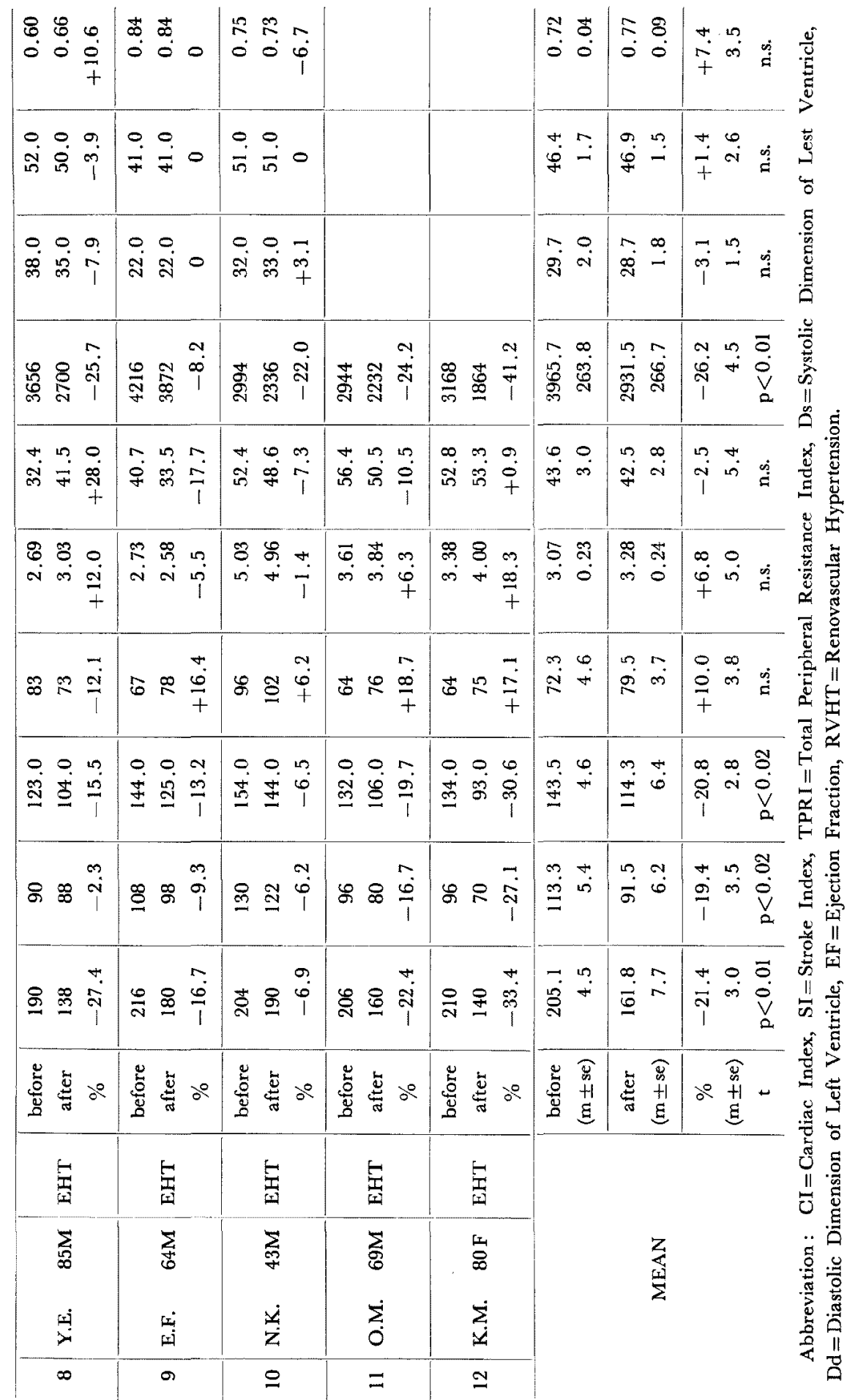


$\mathrm{mmHg}$ systolic and from 70 to $96 \mathrm{mmHg}$ diastolic without any hypotensive agent. Rehabilitation training had been continued uneventfully until January 8, 1977 when the patient suddenly developed coarse tremor in the right lower and upper extremities, disturbance of consciousness and positive Babinski's reflex on the right side. Simultaneously, blood pressure rose sharply to $230 / 110 \mathrm{mmHg}$ and intramuscular injection of $0.3 \mathrm{mg}$ of Reserpine was ineffective. Then, $10 \mathrm{mg}$ of Nifedipine dissolved in $10 \mathrm{ml}$ of water was administered via a gastric tube. Ten min later, blood pressures fell to $145 / 84 \mathrm{mmHg}$, consciousness became clear and tremors disappeared.

Mild paralysis persisted in the right upper and lower extremities, but otherwise recovery was uneventful. Blood pressure remained within normal limit thereafter.

Since urinary excretion of catecholamine and VMA were normal, possibility of pheochromocytoma could be ruled out and electro-encephalogram showed no evidence of epilepsy. This episode was diagnosed as a recurrent attack of cerebrovascular accident.

Group II; In Figs. 3 and 4, changes in blood pressure, heart rate, cardiac index, stroke volume and left ventricular dimension following administration of Nifedipine in patients with severe hypertension are shown.

All patients of this group responded to the therapy with a marked lowering of systolic pressure, on the average, from $205.1 \mathrm{mmHg}$ (range; 170-226 $\mathrm{mmHg}$ ) to $161.8 \mathrm{mmHg}$ (range; $110-190 \mathrm{mmHg}$ ) $(\mathrm{p}<0.01$ ) and from 113.3 $\mathrm{mmHg}$ (range; $90-140 \mathrm{mmHg}$ ) to $91.5 \mathrm{mmHg}$ (range; $56-112 \mathrm{mmHg}$ ) (p< 0.02) diastolic (Table II).

Heart rate increased in 10 patients and decreased slightly in 2, but the increase from 72.3 to 79.5 beats per minute, on the average, was not statistically significant.

Cardiac index increased in 8 patients, showing a tendency of slight rise by $6.8 \%$ from 3.07 to $3.28 \mathrm{~L} / \mathrm{min} / \mathrm{M}^{2}$ on the average(n.s.).

Stroke index decreased only slightly in 9 patients from 43.6 to $42.5 \mathrm{ml}$ / beat $/ \mathbf{M}^{2}$ on the average, but not significantly.

Total peripheral resistance fell markedly in all cases except 1 case (Case 4) from an average of 3965.7 to 2931.5 dynes-sec-cm $\cdot \mathrm{M}^{2}$ or $26.2 \%$ reduction $(\mathrm{p}<0.01)$.

Left ventricular end-diastolic dimension on echocardiogram increased in 1 case (Case 6), but remained uncanged or decreased slightly in other 7 patients. Left ventricular end-systolic dimension decreased in 4, increased slightly in 1, and remained uncanged in 3 patients. Ejection fraction increased in 5, remained unchanged in 2 patients and decreased in 1 . No side effects were observed, except flushing sensation in 1 case (Case 12).

The following is a representative case; (Ciase 9, E.F.) (Fig. 5).

A 64-year-old man was admitted to the hospital for treament of severe hyper- 


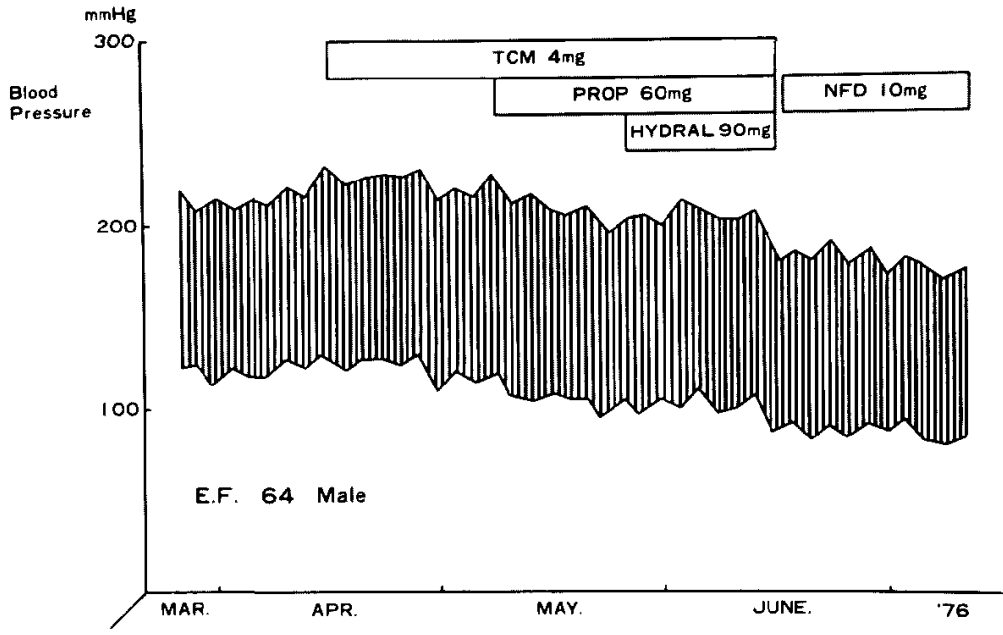

Fig. 5. Treatment and change of blood pressure during hospitalization in case 9 (E.F.).

TCM $=$ Trichlormethiazide, $\mathrm{PROP}=$ Propranolol, $\mathrm{HYDRAL}=$ Hydralazine, $\mathrm{NFD}=$ Nifedipine.

tension. His hypertension had been documented for at least 20 years, and treated with various anti-hypertensive agents unsuccessfully.

On admission on March 25, 1976, the pulse rate was 80 beats per minute and blood pressure was $226 / 130 \mathrm{mmHg}$, without postural hypotension. The other physical abnormalities included left hemiparesis due to cerebrovascular accident which developed 3 years ago and hypertensive retinopathy of grade 3 (Keith-Wegener's classification.)

Cardio-thoracic ratio was $62.4 \%$ and the electrocardiogram showed left ventricular hypertrophy. Laboratory data included hemoglobin concentration of 16.2 $\mathrm{Gm} / 100 \mathrm{ml}$, blood urea nitrogen (BUN) $15.9 \mathrm{mg} / 100 \mathrm{ml}$, serum creatinine 1.2 $\mathrm{mg} / 100 \mathrm{ml}$, serum Na $144 \mathrm{mEq} / \mathrm{L}, \mathrm{K} 3.5 \mathrm{mEq} / \mathrm{L}, \mathrm{Cl} 101 \mathrm{mEq} / \mathrm{L}$, urinalysis showed no abnormal finding and excretion of VMA was within normal limit. Secondary hypertension was excluded by other clinical and laboratory data during the admission.

The patient was given a combination therapy of $4 \mathrm{mg}$ of trichlormethiazide, $60 \mathrm{mg}$ of propranolol, and $90 \mathrm{mg}$ of hydralazine in addition to a low salt diet, but his blood pressure fell only slightly. Following the combination therapy, oral administration of Nifedipine $10 \mathrm{mg}$ was started on June 15, 1976.

When the drug was taken at 8 a.m., blood pressure measurement at 10 a.m. showed a marked fall as shown in Fig. 5.

The hypotensive effects lasted for only 5 to 6 hours. In order to obtain a sustained hypotensive effect, the patient was instructed to take $10 \mathrm{mg}$ of Nifedipine orally every 6 hours.

He was discharged thereafter and has been followed in the out-patient clinic. The hypotensive effect of Nifedipine has not decreased, nor are adverse drug reactions observed. 


\section{Discussion}

Studies on the hypotensive effect of Nifedipine have been reported by Vater $^{3)}$ and Stoepel $^{4)}$ in animal experiments and by Murakami ${ }^{1)}$ and Aoki ${ }^{2}$ in clinical trials.

In all these reports, the drug was used in cases with mild to moderate hypertension. No report is available on the use of Nifedipine in hypertensive crises or in severe intractable hypertension.

At present, injection of hydralazine, diazoxide, minoxidil or sodium nitropurusside is usually used in hypertensive emergencies in Europe and America. ${ }^{5}$ Although the injection of hydralazine, diazoxide or minoxidil has a rapid and remarkable hypotensive effect, it causes a reflex tachycardia and therefore have to be given wih caution in cases complicated by coronary artery disease. ${ }^{6)}$ Moreover, these drugs except hydralazine are not available in Japan, so they are not used in the clinical management of hypertensive emergency.

In the present study, Nifedipine, even when administered orally, showed rapid fall in blood pressure in these hypertensive states. Onset of effect was already observed in $30 \mathrm{~min}$ when capsules were taken orally and within 10 min when it was diluted in water and given via a gastric tube. Thus, in the case of hypertensive encepalopathy with disturbance of consciousness, the content of a capsule could be given by gastric intubation successfully.

Despite a marked fall in blood pressure in a short period of time, a reflex tachycardia rarely occurred, subjective symptoms caused by the fall in blood pressure was not observed and clinical symptoms accompanying hypertension were improved remarkably.

However, the duration of the hypotensive effect was relatively short, with a maximum effect within 30 to $60 \mathrm{~min}$ and became less marked after $180 \mathrm{~min}$. In our clinical trial, a follow-up of more than 3 hours was not done. Aoki et $\mathrm{al}^{7}$, however, reported that the effect of Nifedipine persisted for 7 to 8 hours when $30 \mathrm{mg}$ was given orally.

At present, a combination of hydralazine, bethanidine and/or guanethidine are widely used as anti-hypertensive agents for severe hypertension. But, there are cases in whom these drugs are ineffective or their use is limited due to side-effects.

Nifedipine was proved to be effective in hypertension refractory to these conventional anti-hypertensives. All 12 cases in our study responded to the therapy with a decrease of blood pressure by $21.4 \%$ systolic and $19.4 \%$ diastolic.

A $10.0 \%$ increase in heart rate along with a fall in blood pressure were 
recorded, which is in agreement with findings reported by Murakami' ${ }^{11}$ and Aoki. ${ }^{2)}$ Aoki and co-workers ${ }^{2)}$ interpret the increase in heart rate as due to augmented activity of sympathetic nervous system, since it occurred in parallel with a rise in plasma renin activity.

Cardiac index increased by $6.8 \%$ in this study. According to studies of Lydtin et $\mathrm{al}^{8}$ ) in normal volunteers, a fall in blood pressure and reduction of peripheral vascular resistance accompanied by an increase in cardiac output could not be inhibited by Practolol, a $\beta_{1}$-selective blocker, while the increase in heart rate and shortening of preejection period were diminished, indicating at least in part the contribution of $\beta_{1}$-stimulating effects of Nifedipine.

Van den Brand et $\mathrm{al}^{9)}$ also reported a significant increase in Vmax after administration of Nifedipine, suggesting the possibility that Nifedipine has a positive inotropic effect on the myocardium. Despite many experimental and clinical studies, the inotropic effect of this preparation has remained controversial. $^{3,101-13)}$ Therefore, at present, a reflexogenic increase in heart rate is considered to play a principal role in the increase in cardiac output.

Since a marked reduction of the peripheral vascular resistance was observed along with a fall in the blood pressure, the mechanism of this preparation in lowering the blood pressure is considered primarily due to the peripheral vasodilatation. Similar results were observed in animal experiments, $\left.{ }^{10}\right)$ in lesser degree in healthy subjects ${ }^{8}$ and patients with angina pectoris. ${ }^{14}$ ) These findings are in agreement with the observation reported by Murakami et $\mathrm{al}^{11}$ on patients with hypertension.

In anesthetized dogs, Vater et al $^{3)}$ showed that Nifedipine had a marked vasodilating effect on systemic arteries in addition to the coronary arteries and suggested that its action is more prominent in large arteries in the trunk than in small arteries in the extremities. They also stated that the vasodilating effect of Nifedipine would be due to its inhibition of the adrenaline activity on the smooth muscle rather than its blocking effect on the receptor, since it inhibited the pressor elevation induced by intravenous injection of noradrenaline, angiotensin, or tyramine.

It has been known that $\mathrm{Ca}^{++}$is an important ion to regulate the tonus of smooth muscle. A possible relationship between calium metabolism and pathogenesis of hypertension was suggested by an observation that hypertension was often found among patients with hyperparathyroidism ${ }^{15}$ and hypertension disappeared with normalization of calcium metabolism after surgical opcration thereof. ${ }^{16)}$

When the myocyte is depolarized, availability of $\mathrm{Ca}^{++}$increases to be combined with troponin, consequently inhibition of contraction is lifted. Then, actin and myocin act with each other leading to the contraction of the mus- 
cle. ${ }^{17} \mathrm{Ca}^{++}$involved in the contraction is assumed to be derived from following 2 processes; one released from the sarcoplasmic reticulum in the cell (bound $\mathrm{Ca}^{++}$) and the other transported into the cell via the slow inward current $\left(\mathrm{Ca}^{++}\right.$influx).

According to Imai et al, ${ }^{18)}$ among $\mathrm{Ca}^{++}$antagonists Nifedipine and verapamil inhibit the use of bound $\mathrm{Ca}^{++}$and diltiazem and trimetazidine inhibit both bound $\mathrm{Ca}^{++}$and $\mathrm{Ca}^{++}$influx to suppress the contraction of smooth muscle.

From clinical observations, differences in their effects among $\mathrm{Ca}^{++}$antagonists are noted, particularly in hypotensive effects. While Nifedipine exerts a pronounced hypotensive effect in a short time, diltiazem has a rather mild hypotensive effect by a long-term oral administration, especially in combination with thiazide diuretics. ${ }^{19)}$ However, it was reported that diltiazem showed a potent hypotensive effect in a short time as well as Nifedipine when it was administrated intravenously. ${ }^{20)}$

Although it has been shown that Nifedipine acts on the arterial system and dilate it, its influences on the venous system have not been completely clarified. Mostbeck et al $^{21}$ reported from the study of whole body scanning with a gamma camera after intravenous injection of $99 \mathrm{mTc}$-labelled human albumin, that no shift of the blood volume occurred from the limbs to the trunk after the administration of Nifedipine and stated that this preparation has no dilating effect on the capacitance vessels.

In this respect, this preparation differs from isosorbide dinitrate and sodium nitropurusside, but resembles the action of hydralazine and minoxidil. ${ }^{6}$ )

The present study showed that left ventricular end-diastolic dimension remained unchanged after the administration of Nifedipine in the majority cases and a reduction of afterload may play an importrant role in the increase in ejection fraction. However, possibility of the positive inotropic effect of the agent could neither be confirmed nor excluded from the present study.

\section{REFERENCES}

1. Murakami M, Murakami E, Takekoshi N, Tsuchiya M, Kin T, Onoe T, Takeuchi N, Funatsu T, Hara S, Ishise S, Mifune J, Maeda M: Antihypertensive effect of $4-\left(2^{\prime}-\right.$ Nitrophenyl)-2, 6-dimethyl1,4-dihydropyridine-3,5-dicarbonic acid dimethylester (Nifedipine, Baya 1040), a new coronary dilator. Jap Heart J 13: 128, 1972.

2. Aoki K, Yoshida T, Kato S, Tazumi K, Sato I, Takikawa K, Hotta K: Hypotensive action and increased plasma renin activity by $\mathrm{Ca}^{++}$antagonist (Nifedipine) in hypertensive patients. Jap Heart J 17: 479, 1976

3. Vater W, Kroneberg G, Hoffmeister F, Kaller H, Meng K, Oberdorf A, Puls W, Schlossmann, Stoepel K: Pharmacology of 4-(2'-Nitrophenyl)-2,6-dimethyl-1,4-dihydropyridine-3, 5dicarboxylic acid dimethylester (Nifedipine). Arzneim-Forsch (Drug Res) 22: 1, 1972 
4. Stoepel K: Der Einfluss von Bay a 1040 auf die antibypertensive Wirkung von Reserpin und Methyldopa. Institut für Pharmakologie Pharma-Bericht Nr 5212: 1, 1975

5. Koch-Weser J: Current concepts. Hypertensive emergencies. New Eng J Med 290: 211, 1974

6. Koch-Weser J: Vasodilator drugs in the treatment of hypertension. Arch Intern Med 133: 1017,1974

7. Aoki K, Yoshida M, Kondo S, Mochizuki A, Takikawa S: Anti-hypertensive effect of $\mathrm{Ca}^{++}$ antagonistic drugs to hypertensive patients. Proc J Jap Soc Intern Med 65: 104, 1976

8. Lydtin H, Lohmöller R, Schmits H, Walter I: Hemodynamic studies on Adalat in healthy volunteers and in patients. Proc 2nd International Adalat Symposium. New Therapy of Ischemic Heart Disease (ed by Lochner W, Braasch W, Kroneberg G), Springer, Berlin, p. 112, 1975

9. Van den Brand M, Remme WJ, Meester GT, Tiggelaar-de Widt I, re Ruiter R, Hugenholtz $\mathrm{PZ}$ : Changes in left and right ventricular haemodynamics in angina pectoris patients following Adalat administration. Proc 3rd International Adalat Symposium. New Therapy of Ischemic Heart Disease (ed by Jatene AD, Lichtlen PR), Excerpta Medica, AmsterdamOxford, p. 69, 1975

10. Kirchheim H, Gross R: Hemodynamic effects of Adalat in the unanesthetized dog. Proc 2nd International Adalat Symposium. New Therapy of Ischemic Heart Disease (ed by Lochner W, Braasch W, Kroneberg G), Springer, Berlin, p. 82, 1975

11. Kober G, Becker HJ, Kaltenbach M: Left ventricular hemodynamics in patients at rest before and after Nifedipine (Adalat). Proc 2nd International Adalat Symposium. New Therapy of Ischemic Heart Disease (ed by Lochner W, Braasch W, Kroneberg G), Springer, Berlin, p. 164, 1975

12. Fleckenstein A, Tritthart H, Döring H], Byon KY: Bay a 1040-ein hochaktiver Ca ${ }^{++}$antagonistischer Inhibitor der electromechanischen Koppelungsprozesse im Warmblüter-Myokard. Arzneim-Forsch 22: 22, 1972

13. d'Oliveira J, Galderon NR, Garcilazo E, Patricio J, Tenreyro E: Hemodynamic changes after a single dose of Nifedipine (Adalat). Proc 3rd International Adalat Symposium. New Therapy of Ischemic Heart Disease (ed by Jatene AD, Lichtlen PR), Excerpta Medica, Amsterdam, p. 50, 1975

14. Van den Brand M, Remme WJ, Meester GT, Tiggelaar-deWidı I, deRutter R, Hugenholtz PG: Hemodynamic effect of Nifedipine (Adalat) in patients catheterized for coronary artery disease. Proc 2nd International Adalat Symposium. New Therapy of Ischemic Heart Disease (ed by Lochner W, Braasch W, Kroneberg G), Springer, Berlin, p 145, 1975

15. Hellström J: Experience from one hundred and five cases of hyperparathyroidism. Acta Chir Scand 113: 501, 1975

16. Blum M, Kirslen M, Worth MH: Reversible hypertension. Cuased by the hypercalcemia of hyperparathyroidism, Vitamin D toixicity and calcum infusion. JAMA 237: 262, 1977

17. Ebashi S, Endo M: Progr Biophys Mol Biol 18: 123, 1968

18. Takeda K, Imai S: Pharmacology of anti-anginal drugs. J Practical Pharmacy 25: 21, 1974

19. Kawai Y, Yamamoto Y, Oyama T, Yamazami K, Yasutomi E, Iwasaki T, Ito S: Effectiveness of Diltiazem hydrochloride in hypertension. J Adult Disease 5: 1495, 1975

20. Takeda T, Ishii A, Ohno K, Ikeda S, Nakamura Y, Matsuoka H: Effect of Diltiazem hydrochloride (CDR-401) to renal hemodynamics and renal function. Proc 17 th Jap Soc Nephrology, 1974

21. Mostbeck A, Partsch H, Peschl L: Investigations on peripheral blood distribution. Proc 3rd International Adalat Symposium. New Therapy of Ischemic Heart Disease (ed by Jatene AD, Lichtlen P), Excerpta Medica, Amsterdam, p. 91, 1975 